\title{
Faculty Publishing Productivity: Comparisons over Time
}

\author{
John M. Budd
}

Concerns about higher education abound, and these include concerns about productivity. The present study extends two previous examinations of faculty publishing productivity covering the years 1991 to 1993 and 1995 to 1997 . Both members of ARL and a group of institutions included in ACRL's data set are included. For both groups there are some increases in mean total numbers of publications, although the rate of increase has decreased since the second time period. Per capita rates of publication demonstrate an even flatter pattern. In recent years, there have been some changes in the dynamics of universities' faculties; there are more part-time faculty and more faculty who are not on the tenure track. These factors, coupled with the publishing data, point to activities that all academic librarians should be aware of.

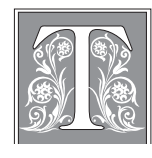

he self-directed motivation and the institutional impetus in higher education to inquire and to publish the fruits of inquiry have not changed materially for a number of years. Tenure and promotion decisions, by and large, are still based on quantitative measures of productivity. Although the culture has remained quite constant, the information landscape has continued to shift. Over the past several years, serials publishers and aggregators have made thousands of journal titles available to scholars electronically. Individual academic libraries and consortia have access to more serials titles as a result of the licensing of services and packages. A result is that more libraries, and thus the scholars at the universities, have access to more serials than ever before. Further, the entire academic community has greater access to information than ever before. The realization of the magnitude of access can prompt some questions. Given the numbers of titles and the scope of the contents of those titles, where does the content come from? Universities are a primary source for the researchers who write and publish. This is not a surprise as research is one of the missions of universities.

Rankings by US News \& World Report, the National Research Council, and others frequently include metrics that account for numbers of publications, among other variables. In short, more publications can lead to higher rankings of academic programs and entire institutions. For example, Robert G. Green, Melissa H. Bellin, and Frank R. Baskind reported that, in social work programs, twelve of the sixty-one doc-

John M. Budd is Professor and Associate Director in the School of Information Science E Learning Technologies at the University of Missouri-Columbia; e-mail: buddj@missouri.edu. 
toral programs' faculties are responsible for 43 percent of the journal articles published in the field. Further, the rankings of the programs correlated highly with publishing productivity. ${ }^{1}$ Robert K. Toutkoushian and others conducted an examination of faculty publications (total and per capita). They ranked the universities by the two measures and then compared those rankings to overall National Research Council and US News $\mathcal{E}$ World Report rankings. The authors concluded that: "Given the increasing emphasis on performance indicators, the measure of the ratio of publications to full-time faculty member can fill an important gap in how institutions are evaluated and compared." 2

The nature of rankings and the emphasis on research and publication at some universities can be the subject of inquiry and commentary, but they are not the focus of the present examination. The principal purpose of this examination can be simply stated. It follows up on two previously conducted studies and provides some comparison over time. The two central questions asked here mirror those of the previous works: (1) What is the publishing output of faculty affiliated with members of the Association of Research Libraries and with the data set provided by the Association of College and Research Libraries? and (2) What changes in publishing patterns have occurred over the years of the three studies?

\section{The Study}

This work builds on two previous studies by John M. Budd. The first of the two published works examined faculty publishing activity at Association of Research Libraries (ARL) institutions from 1991 through 1993. ${ }^{3}$ It used as data sources the Science Citation Index, the Social Sciences Citation Index, and the Arts \& Humanities Citation Index. The second study also used the citation indexes and added institutions included in Association of College and Research Libraries (ACRL) data reports. The time period for the later study was 1995 through 1997.4 By way of brief summary, it can be said that all publishing trends increased from the first to the second time period. For both the ARL and the ACRL populations, the mean institutional and the mean per capita publications rose from 1991-1993 to 1995-1997. The conclusion of the second study warned that: "As principals involved in the production of publications, the faculty should be involved in the decision-making processes that will shape scholarly communication." ${ }^{5}$ To date, faculty have had little influence over the rewards structure and have reacted to university policies by increasing publication rates. Also, technological applications have served to alter access mechanisms, but not to affect fundamental communication practices, especially publication.

The present study extends the previous two to the period 2002 through 2004. The principal reason for investigating the matter of faculty publishing once again is to enable comparisons with the past. As is the case with the two previous studies, the citation indexes, available online as Web of Science, is the source of publication data for this investigation. As is stated above, the time period in question is 2002 though 2004. The coverage of Web of Science is not exhaustive; it includes many titles (nearly 9,000) in the sciences, the social sciences, and the arts and humanities. This is actually a fraction of the journals published; because of this limitation, a subset of potential publishing venues is included here. Web of Science covers journal literatures, so publication of book or book chapters is not included. The resource does cover many types of serial publication, but, as in the previous studies, only the publications designated as "articles" are counted. Book reviews, editorials, and so on are excluded.

Web of Science enables searching by organization, so each university can be searched individually. In the cases of multicampus systems, such as the University of Texas or the University of Wisconsin, specific cities also can be searched. Thus, 
institutions can be combined with cities so that the publications emanating specifically from the University of Texas at Austin or the University of Wisconsin, Madison, can be obtained. Another caveat from the previous studies bears repeating here. The scope of a university's activities may vary from institution to institution. To be specific, in some cases a medical school is attached to a university's main campus, so the publications by medical school faculty are counted. If, on the other hand, a medical school is located in a different city from the main campus, its publications are not counted. The numbers, then, contain some discrepancies, but adhering to this means of data gathering more readily enables comparison over time.

\section{Findings: ARL Institutions}

In the two previous studies, the mean publications per institution were $4,595.8$ and 5,493.5, respectively. Given the numbers of journals being produced and the continuing pressures on faculty to publish, it may be expected (all other things being equal) that the institutional mean would rise and, in fact, it has. For the 2002-2004 period, the mean number of publications per institution is 6,078.2. The range is 776 to 23,728 . To offer another perspective on the magnitude of publishing activity, the total number of articles by faculty at the ARL member universities during the three years is more than 550,000. Comparison of the top twenty institutions for all three periods is presented in table 1.

\begin{tabular}{|l|r|l|r|l|r|}
\hline \multicolumn{5}{|c|}{ TABLE 1 } \\
Top Twenty ARL Institutions Compared: Total Number of Publications \\
\hline \hline \multicolumn{2}{|c|}{$1991-1993$} & \multicolumn{2}{c|}{ 1995-1997 } & \multicolumn{2}{c|}{ 2002-2004 } \\
\hline Harvard & 16,945 & Harvard & 21,913 & Harvard & 23,728 \\
\hline UCLA & 12,566 & UCLA & 13,620 & UCLA & 15,083 \\
\hline MIT & 11,788 & Michigan & 13,006 & Washington & 14,335 \\
\hline Michigan & 10,097 & UC Berkeley & 12,237 & Michigan & 13,857 \\
\hline Washington & 10,645 & Washington & 12,117 & Johns Hopkins & 13,760 \\
\hline Cornell & 10,518 & Minnesota & 11,369 & UC Berkeley & 13,055 \\
\hline UC Berkeley & 10,378 & Stanford* & 11,169 & UC San Diego & 12,947 \\
\hline Minnesota & 10,304 & Wisconsin & 10,952 & Pennsylvania & 12,274 \\
\hline Stanford* & 9,723 & Cornell & 10,918 & Wisconsin & 11,427 \\
\hline Wisconsin & 9,663 & Johns Hopkins & 10,576 & Columbia & 10,990 \\
\hline Johns Hopkins & 9,636 & Pennsylvania & 10,247 & Cornell & 10,795 \\
\hline Pennsylvania & 8,636 & UC San Diego & 10,059 & MIT & 10,083 \\
\hline Illinois & 7,884 & Pittsburgh & 9,148 & Penn State & 10,018 \\
\hline Columbia & 7,824 & Yale & 8,938 & Ohio State & 9,589 \\
\hline Yale & 7,779 & Columbia & 8,886 & Florida & 9,577 \\
\hline UC San Diego & 7,732 & MIT & 8,732 & Minnesota & 9,479 \\
\hline UC Davis & 7,621 & Ohio State & 8,552 & Yale & 9,377 \\
\hline Ohio State & 7,155 & Penn State & 8,543 & Pittsburgh & 9,343 \\
\hline Pittsburgh & 7,155 & Illinois & 8,400 & Duke & 8,952 \\
\hline Penn State & 6,925 & UC Davis & 8,380 & UC Davis & 8,945 \\
\hline *Stanford withdrew from ARL between the second and third studies. & \\
\hline
\end{tabular}




\begin{tabular}{|l|r|l|r|l|r|}
\hline \multicolumn{5}{|c|}{ TABLE 2 } \\
\hline \multicolumn{2}{|c|}{ Top Twenty ARL Institutions Compared: Per Capita Publications } \\
\hline \hline 1993 & \multicolumn{2}{c|}{ 1995-1997 } & \multicolumn{2}{c|}{ 2002-2004 } \\
\hline Johns Hopkins & 12.71 & Harvard & 12.94 & Harvard & 11.88 \\
\hline Harvard & 11.46 & Johns Hopkins & 12.03 & Johns Hopkins & 11.46 \\
\hline MIT & 11.26 & Wash. U. (MO) & 11.14 & Duke & 9.86 \\
\hline Wash. U. (MO) & 10.24 & MIT & 10.39 & Wash. U. (MO) & 9.72 \\
\hline UCLA & 7.51 & Duke & 10.32 & UC Berkeley & 9.41 \\
\hline UC San Diego & 7.34 & UC Berkeley & 9.87 & UC San Diego & 8.64 \\
\hline UC Berkeley & 7.06 & Rochester & 9.85 & Pennsylvania & 8.60 \\
\hline Stanford* & 6.92 & UC San Diego & 9.38 & Case Western & 8.36 \\
\hline Minnesota & 6.90 & UCLA & 7.93 & UCLA & 8.06 \\
\hline Cornell & 6.81 & Stanford* & 7.79 & Columbia & 7.47 \\
\hline Brown & 5.79 & Minnesota & 7.58 & UC Santa Barbara & 7.35 \\
\hline Princeton & 5.46 & Cornell & 7.36 & Princeton & 6.81 \\
\hline Chicago & 5.16 & Brown & 7.12 & Brown & 6.61 \\
\hline So. California & 5.04 & Emory & 7.10 & Cornell & 6.57 \\
\hline UC Davis & 4.96 & UC Davis & 6.49 & Minnesota & 6.08 \\
\hline Virginia & 4.82 & Princeton & 6.20 & Yale & 5.89 \\
\hline Utah & 4.79 & Iowa & 6.04 & Georgia Tech & 5.81 \\
\hline Michigan & 4.64 & Pittsburgh & 5.88 & UC Irvine & 5.69 \\
\hline Maryland & 4.61 & Chicago & 5.83 & Iowa & 5.67 \\
\hline Pennsylvania & 4.61 & UC Riverside & 5.72 & Wisconsin & 5.55 \\
\hline *Stanford withdrew from ARL between the second and third studies. & \\
\hline
\end{tabular}

It should be noted that Stanford's absence from the present study is a result of the university's decision to withdraw from ARL. It also bears repeating that the inclusion of only the publications produced by faculty at a university's main campus has an impact on rankings. For example, if the University of Texas medical school at Galveston were included, the University of Texas at Austin would rank eighteenth for 2002-2004 (the base number of 7,027 plus 2,410 for the medical school). Other institutions also would be affected; Louisiana State University's total would rise from 4,006 to 5,245 if the New Orleans medical school were counted. It also is apparent from the table that some institutions moved (upward or downward) over time. The University of California,
San Diego, not only increased its number of publications, but its ranking improved with each time period. The University of Illinois, on the other hand, saw its ranking fall to the point where it no longer ranked in the top twenty by the third study.

In addition to total numbers of publications, the mean per capita publications by institution can be calculated. The source for faculty numbers for each university is ARL's interactive statistics. ${ }^{6}$ For the $1991-$ 1993 period, the per capita mean was 3.56; that mean rose to 4.20 in 1995-1997. For 2002-2004, the per capita mean is 4.24 , only a slight increase over the previous time period. The range is 0.71 to 11.88 . The top twenty institutions over the three periods is presented in table 2 (again, with Stanford absent for 2002-2004). 
As mentioned above, recent years have seen some changes in the composition of university faculty. The impact of the shift is not possible to determine, but the reported numbers of institutional faculty reported by ARL may include both tenured/tenure-track and non-tenure-track faculty. To use one institutional example again, it is apparent that the University of Missouri-Columbia reported the total number of faculty to ARL. An accurate count of faculty could influence the per capita figures. The impact of changing proportions of tenure-track versus nontenure-track is discussed below.

In Budd's second study, a couple of hypotheses were tested, based on comparisons of the data from the 1991-1993 and 1995-1997 time periods. These hypotheses also can be tested with the 1995-1997 and 2002-2004 sets of data. The hypotheses, stated as null, are:

$\mathrm{H}_{1}$ There is no statistically significant difference between the mean numbers of publications per institution for the two time periods.

$\mathrm{H}_{2}$ There is no statistically significant difference between the mean per capita numbers of publications for the two time periods.

Also as in the previous work, the type I error level (the probability of rejecting a true null hypothesis) used is 0.05 . To test the two hypotheses, the paired t-test (a test of differences between means) is employed. In the cases of both mean publications per institution and mean per capita publications, the calculated probability is greater than 0.05 . Neither null hypothesis can be rejected; there are no statistically significant differences between the two periods.

Some library- and institution-based data also can be compared to the publication data. In other words, some additional examination can indicate whether there are strong correlations between publications and such measures as volumes held by the libraries, total materials expenditures by libraries, and PhDs awarded by the universities. The first and third of the measures were analyzed in the second study by Budd; the second is added here to determine if there are any additional indications of connection. Rank-order correlation is used here to compare the rankings of universities by total publications and per capita publications and the ranking by the three measures stated above. The correlations do not indicate any causal relationships, but the connections between publications and other measures may provide some indicators of linkages. The correlations are presented in table 3 (along with the correlations for volumes held and for PhDs awarded for the previous two time periods).

As is evident from the table, where comparison is possible over time, the correlation coefficients are generally slightly higher. Focusing on the per capita measures, the comparison between these and total volumes held by the library indicates

\begin{tabular}{|l|c|c|c|}
\hline \multicolumn{5}{|c|}{ TABLE 3 } \\
Rank-Order Correlations (ARL Institutions): Comparisons over Time \\
\hline \hline & $\mathbf{1 9 9 1 - 1 9 9 3}$ & $\mathbf{1 9 9 5 - 1 9 9 7}$ & $\mathbf{2 0 0 2 - 2 0 0 4}$ \\
\hline Total publications by volumes in library & .69 & .70 & .72 \\
\hline Per capita publications by volumes in library & .42 & .40 & .46 \\
\hline Total publications by PhDs awarded & .79 & .83 & .83 \\
\hline Per capita publications by PhDs awarded & .48 & .45 & .45 \\
\hline Total publications by materials expenditures & & & .74 \\
\hline Per capita publications by materials expenditures & & & .65 \\
\hline
\end{tabular}




\begin{tabular}{|l|r|l|r|l|r|}
\hline \multicolumn{5}{|c|}{ TABLE 4 } \\
\hline \multicolumn{2}{|c|}{ Top Twenty ACRL Institutions Compared: Total Number of Publications } \\
\hline \hline \multicolumn{2}{|c|}{$1991-1993$} & \multicolumn{2}{c|}{$1995-1997$} & \multicolumn{2}{c|}{ 2002-2004 } \\
\hline Tufts & 2,883 & Tufts & 3,811 & Alabama, Birm. & 4,889 \\
\hline VCU & 2,521 & VCU & 2,816 & Tufts & 3,864 \\
\hline Carnegie Mellon & 2,372 & Carnegie Mellon & 2,744 & Carnegie Mellon & 3,552 \\
\hline South Florida & 2,359 & South Florida & 2,679 & Wake Forest & 2,842 \\
\hline Kansas State & 2,006 & Kansas State & 2,313 & UC Santa Cruz & 2,818 \\
\hline Vermont & 1,702 & West Virginia & 1,965 & VCU & 2,779 \\
\hline Louisville & 1,557 & Vermont & 1,851 & South Florida & 2,769 \\
\hline West Virginia & 1,515 & St. Louis U. & 1,846 & Kansas State & 2,548 \\
\hline St. Louis U. & 1,485 & UC Santa Cruz & 1,832 & Louisville & 2,327 \\
\hline UC Santa Cruz & 1,447 & Louisville & 1,663 & Clemson & 2,010 \\
\hline Clemson & 1,358 & Clemson & 1,528 & Northeastern & 2,000 \\
\hline UW, Milwaukee & 1,296 & Northeastern & 1,528 & St. Louis U. & 1,988 \\
\hline Northeastern & 1,259 & UW, Milwaukee & 1,515 & Vermont & 1,902 \\
\hline Rhode Island & 1,255 & Rhode Island & 1,399 & West Virginia & 1,862 \\
\hline Baylor & 1,224 & Utah State & 1,363 & Drexel & 1,598 \\
\hline Utah State & 1,147 & Nevada-Reno & 1,347 & Central Florida & 1,531 \\
\hline Arkansas & 1,057 & Arkansas & 1,233 & Arkansas & 1,506 \\
\hline Nevada-Reno & 1,024 & North Texas & 1,148 & Nevada-Reno & 1,470 \\
\hline Wyoming & 1,017 & Lehigh & 1,139 & Georgia State & 1,451 \\
\hline Akron & 1,014 & New Mexico St. & 1,102 & UW, Milwaukee & 1,380 \\
\hline
\end{tabular}

a mixed, but overall upward, trend. The coefficient for 1991-1993 is .42; the one for 1995-1997 is .40; the coefficient for the last time period is .46. The trend for per capita publications compared with PhDs awarded is similarly flat: .48 to .45 to .45 . When comparing total publications and total volumes held by the library, the coefficient rises over the three time periods from .69 to .70 to .72 . A similar trend occurs with the comparison between total publications and PhDs awarded: .79 to .83 to .83 .

Again, these correlations do not indicate causation, but they may be somewhat indicative of some conjoined variance. That is, the factors that affect the number of volumes held by the library and doctoral students that can matriculate and the factors that affect publication activity may be similar. The numbers of volumes held can be an indication of sustained financial support for the libraries so that a history of acquisitions can be chronicled. If the financial support for faculty activities is similar to that for libraries and for doctoral students, publication also may be enhanced. To extend the point, the ability of the institution to support doctoral students may be linked with the increased potential for collaborative publication (between faculty and students). Because of the relatively high correlation coefficients related to total volumes, a measure is added to the present study - total materials expenditures. The coefficient for total publications compared to total materials expenditures is .74. The coefficient for per capita publications compared to total materials expenditures is .65. 


\section{Findings: ACRL Institutions}

In the study of 1995-1997 data, Budd stated that: "ACRLinstitutions are included in the present study in order to gain insight into whether the trends that are evident among ARL institutions occur in other universities." 7 The institutions included in that investigation are not as extensively engaged in research as are the ARL members. As is the case with the ARL population, the ACRL institutional data can be examined over time. The mean for total publications per university in 1991-1993 was 874.0 ; for $1995-1997$, the mean was $1,074.9$. For the $2002-2004$ period, the mean is $1,158.8$ (the range is 122 to 4,889 ). The top twenty institutions by total publications are presented in table 4.

The trend for per capita publications is a bit less clear. The mean for the first time period was 1.59; the mean for the second time period was 1.78. In each of those studies Tufts University had the highest per capita mean, with 9.55 and 12.33 . Tufts's total publications are in line with the past, but the reported number of faculty is higher at this time than in the past. The source of faculty sizes is the 2003 edition of Academic Trends E Statistics, published by ACRL. ${ }^{8}$ If the previous high per capita figures for Tufts are controlled for, the means for the previous sets of years come down a bit, to be almost flat across all three time periods. The top twenty universities for the three time periods by mean per capita publications are presented in table 5 .

Once again, these data allow for the testing of two hypotheses. The two hypotheses, again stated as null, are very similar to those used with the ARL data:

\begin{tabular}{|l|r|l|r|l|r|}
\hline \multicolumn{5}{|c|}{ TABLE 5 } \\
Top Twenty ACRL Institutions Compared: Per Capita Publications \\
\hline \hline \multicolumn{2}{|c|}{$1991-1993$} & \multicolumn{2}{c|}{ 1995-1997 } & \multicolumn{2}{c|}{ 2002-2004 } \\
\hline Tufts & 9.55 & Tufts & 12.33 & Alabama, Birm. & 6.39 \\
\hline Carnegie Mellon & 4.30 & Carnegie Mellon & 4.79 & Tufts & 5.02 \\
\hline Clarkson & 3.83 & UC Santa Cruz & 4.51 & UC Santa Cruz & 4.99 \\
\hline UC Santa Cruz & 3.37 & Clarkson & 3.96 & Carnegie Mellon & 4.06 \\
\hline VCU & 3.16 & St. Louis U. & 3.61 & VCU & 3.33 \\
\hline Vermont & 2.90 & Alaska-Fairbanks & 3.18 & South Florida & 3.19 \\
\hline Texas-Dallas & 2.48 & Lehigh & 2.85 & Idaho & 2.63 \\
\hline Lehigh & 2.32 & Nevada-Reno & 2.72 & Louisville & 2.63 \\
\hline Kansas State & 2.31 & Vermont & 2.52 & Wake Forest & 2.47 \\
\hline Baylor & 2.08 & Drexel & 2.37 & Northeastern & 2.41 \\
\hline Utah State & 2.02 & Rhode Island & 2.22 & Lehigh & 2.39 \\
\hline Nevada-Reno & 2.00 & Montana State & 2.12 & Vermont & 2.39 \\
\hline Rhode Island & 1.91 & CO School Mines & 2.10 & West Virginia & 2.63 \\
\hline CO School Mines & 1.85 & Northeastern & 2.05 & Kansas State & 2.21 \\
\hline Idaho & 1.83 & Texas-Dallas & 1.95 & Central Florida & 2.16 \\
\hline Drexel & 1.79 & Kansas State & 1.92 & Nevada-Reno & 2.16 \\
\hline Missouri-Rolla & 1.77 & Utah State & 1.90 & Utah State & 2.00 \\
\hline St. Louis U. & 1.77 & VCU & 1.88 & Georgia State & 1.98 \\
\hline Wyoming & 1.70 & UW, Milwaukee & 1.84 & Wyoming & 1.98 \\
\hline Clark & 1.69 & SUNY-Bing. & 1.81 & Clemson & 1.96 \\
\hline
\end{tabular}


$\mathrm{H}_{1}$ There is no statistically significant difference between the mean numbers of publications per institution for the two time periods.

$\mathrm{H}_{2}$ There is no statistically significant difference between the mean per capita numbers of publications for the two time periods.

Also once again, the type I error level is set at 0.05 .

The paired t-test is employed as the means to test the hypotheses and to determine if there are statistically significant differences between means. As is the case with the ARL data, there are no statistically significant differences between the two sets of means. This means that the two null hypotheses cannot be rejected. There is some increase in the mean total publications, but, as noted above, the mean per capita publication rates are flat.

Rank-order correlations do demonstrate some changes in the relationships of publication activity and some library and institutional measures. The correlation coefficients for the three time periods are presented in table 6 .

The correlations for mean total publications and total volumes in libraries have not moved a great deal over the years. However, the correlations for mean total publications and PhDs awarded have risen over time: .42 to .44 to .51 . The changes in the relationships between mean per capita publications and the two measures are more pronounced. Comparison with total volumes in libraries moved from .05 to .00 to .19 . The changes with regard to PhDs awarded are even clearer, from .11 to .12 to .52 . As is also the case with the ARL universities, comparisons with total materials expenditures reveal relatively strong correlations. The coefficient for mean total publications and expenditures is .65, and the coefficient for mean per capita publications and expenditures is .59. The indication is that the factors contributing to materials expenditures also may be contributing to publication activities.

\section{Discussion}

Although the form of journal literature has been altered somewhat (traditional print journals also are available online through a number of sources), faculty at universities continue to publish in substantial numbers. The increases have moderated, but increases in total publications are still evident. The tripartite mission of universities - teaching, service, and research-continues to contain an emphasis on the third part. Given the magnitude of the activity, not only on extensive research institutions, but on others as well, a well-supported infrastructure is needed. This infrastructure includes laboratories, equipment, and information services and access. The research and publishing activities of faculty rely on a level of institutional support that extends to all elements of the process of inquiry. The correlation coefficients, reported above, that relate to libraries' materials

\begin{tabular}{|l|c|c|c|}
\hline \multicolumn{5}{|c|}{ TABLE 6 } \\
\multicolumn{2}{|c|}{ Rank-Order Correlations (ACRL Institutions): Comparisons over Time } \\
\hline \hline & $\mathbf{1 9 9 1 - 1 9 9 3}$ & $\mathbf{1 9 9 5 - 1 9 9 7}$ & $\mathbf{2 0 0 2 - 2 0 0 4}$ \\
\hline Total publications by volumes in library & .28 & .36 & .34 \\
\hline Per capita publications by volumes in library & .05 & .00 & .19 \\
\hline Total publications by PhDs awarded & .42 & .44 & .51 \\
\hline Per capita publications by PhDs awarded & .11 & .12 & .52 \\
\hline Total publications by materials expenditure & & & .65 \\
\hline Per capita publications by materials expenditure & & & .59 \\
\hline
\end{tabular}


expenditures indicate a connection between the financial support provided by the institutions and the productivity of the faculty. This financial support may be complex at this time. If there are largescale alterations in the mode, media, and financing of publication in the coming years, the past trends may not be an adequate indicator of future activity. An explosion of Open Access journals could have an impact, for example, but only if the peer-review processes also are transformed. If, as Richard C. Atkinson has argued, the purpose is greater accessibility to research results and scholarship, ${ }^{9}$ the findings presented here may not look foreign at some future date.

The comparison presented here may be particularly important in light of some changes in higher education in recent years. Pressures and motivation to conduct research and to publish may not have diminished recently, but some shifts should be pointed out. Although tenure and promotion criteria do not seem to have altered appreciably, some other dynamics related to have shifted. For example, according to the National Center for Education Statistics (NCES), the percentage of part-time faculty, as a proportion of the total, rose from 32.3 percent in 1995 to 44.5 percent in 2001. ${ }^{10}$ Other indicators should also be noted; the percentage of all faculty at four-year institutions with tenure fell from 53.5 percent in 1997-1998 to 48.7 percent in 2001-2002. ${ }^{11}$ Further, according to the IPEDS, the percentage of full-time faculty not on the tenure track increased from 21.9 percent in 1995 to 28.1 percent in $2001 .{ }^{12}$ By 2003 , the percentage of full-time faculty at public doctoral universities was 30.3 percent. ${ }^{13}$ To take a single institution as one more example, the percentage of "nonregular" (non-tenure-track) faculty at the University of Missouri-Columbia increased from 17.5 percent in 1997 to 23.5 percent in $2002 .{ }^{14}$ Extrapolation from these figures is a matter of speculation, but if we do assume that the reduction in the proportion of faculty on the tenure track is concomitant with publishing activity, the institutional average for the ARL members might jump from 6,078 to 6,455 (a 6.2\% difference). If this difference also holds for the ACRL institutions, their mean might shift from 1,159 to 1,231.

The aforementioned trends may not be surprising to anyone who has followed higher education activities over the past several years, but they do have relevance to this study. If a smaller proportion of an institution's faculty is tenured or on the tenure track, it might be assumed that the total number of publications produced by a university would not increase over time. Given the downturn in the percentage of a university's faculty being tenured or on the tenure track, curiosity about publishing patterns begs for examination. For instance, if the trends in faculty demographics continue, there could eventually be a downturn in the total numbers of articles published. Such trends might have an impact on the futures of specific journal titles. That outcome could be a simple one compared to others. If the shift from tenure-track to non-tenure-track faculty is uneven across disciplines, the intellectual and research bases of entire fields could be affected. In short, both supply (the numbers of kinds of publications being produced) and demand (the faculty who are active researchers and users of published research) could be altered in ways that affect the purposes of the university library. It is essential that our profession watch all of these interrelated phenomena closely so that libraries are not in a merely reactive stance.

\section{Notes}

1. Robert G. Green, Melissa H. Bellin, and Frank R. Baskind, "Results of the Doctoral Faculty Publication Project: Journal Article Productivity and Its Correlates in the 1990s," Journal of Social Work Education 38 (Winter 2002): 135-52. 
2. Robert K. Toutkoushian and others, "Using Publications Counts to Measure an Institution's Research Productivity," Research in Higher Education 44 (Apr. 2003): 143.

3. John M. Budd, "Faculty Publishing Productivity: An Institutional Analysis and Comparison with Library and Other Measures," College \& Research Libraries 56 (Nov. 1995): 547-54. Data and findings from the 1991-1993 period are taken from this source.

4. - "Increases in Faculty Publishing Activity: An Analysis of ARL and ACRL Institutions," College \& Research Libraries 60 (July 1999): 308-15. Data and findings from the 1995-1997 period are taken from this source.

5. Ibid., 314.

6. Association of Research Libraries, "WWW Interactive Edition of ARL Statistics Data. Available online from http://www.arl.org/stats/arlstat/index.html. [Accessed 3 March 2005].

7. Budd, "Increases in Faculty Publishing Activity," 312.

8. Association of College \& Research Libraries, 2003 Academic Library Trends \& Statistics for Carnegie Classification: Doctorate-granting Institutions (Chicago: ACRL, 2004).

9. Richard C. Atkinson, "A New World of Scholarly Communication," Chronicle of Higher Education 50 (Nov. 7, 2003): B16.

10. U.S. Department of Education, National Center for Education Statistics, Digest of Education Statistics: 2003 (Washington, D.C.: NCES, 2004), 291.

11. Ibid., 309.

12. U.S. Department of Education, Integrated Postsecondary Education Data System, "Changing Composition of Faculty at Public and Private Four-year Institutions, 1989-2001, Two-year Intervals." Available online from http://www.aaup.org/surveys/zrep.htm. [Accessed 10 March 2005].

13. U.S. Department of Education, National Center for Education Statistics, 2004 National Study of Postsecondary Faculty: Report on Faculty and Instructional Staff in Fall 2003 (Washington, D.C.: NCES, 2005), 12.

14. University of Missouri-Columbia, “Number of Full-time Ranked Faculty.” Available online from http://www.missouri.edu/ ir/pages/personnel/faculty/ftrnkten88.pdf. [Accessed 10 March 2005]. 